\title{
Simulation of Soil Behavior Following the Passage of Tractors
}

\author{
Anis Elaoud ${ }^{12^{*}}$, Sayed Chehaibi ${ }^{1}$ and Khaoula Abrougui ${ }^{1}$ \\ ${ }^{1}$ Higher Institute of Agronomy Chott-Mariem 4042 Sousse (Tunisia) \\ ${ }^{2}$ Higher Engineering School for Rural Equipment Medjez Elbeb (Tunisia) \\ Accepted 10 Feb 2015, Available online 20 Feb 2015, Vol.5, No.1 (Feb 2015)
}

\begin{abstract}
In order to improve and develop the Tunisian agriculture, the government has encouraged the introduction of modern technologies and has also promoted the adoption of innovative practices cultures. Indeed, the extensive use of mechanization increases the crop productivity but its inadequate application also has adverse effects on the soil caused by the phenomenon of compaction. Which will cause the loss of soil fertility and increased production costs. This problem increases with increase the stress on contact wheel/soil. For this reason, the objective of this study is to simulate the footprint of the soil/tire three types of tractor after their passage on a sandy loam soil type contact. The analysis using was performed Specific database (TERRANIMO). Simulation parameters are based on the choice of tractors masses respectively $6500 \mathrm{~kg}, 4400 \mathrm{~kg}$ and $10500 \mathrm{~kg}$. The main results obtained have shown that the tractor the heavier caused constraint wheel rear/soil caused which exceeds $100 \mathrm{kPa}$. As against, the second tractor wheel rear/soil has spawned a constraint $50 \mathrm{kPa}$. Comparing the two results showed that the tractor $6500 \mathrm{~kg}$ achieved a serious and excessive compaction which begat a negative impact on soil quality and crop yields. Simulation parameters were based on the choice of two inflation pressures of the rear wheels (1.6 bars and 2.1 bars) and those of the front wheels (0.8 and 1.6 bar). Main results shows an increase rear tire pressure by $31 \%$ matches to an increase in the maximum stress at $27 \%$, and increase front tire pressure by $100 \%$ matches to an increase in the maximum stress at $80 \%$.
\end{abstract}

Keywords: Wheel traffic, Tractor, Soil compaction, Simulation.

\section{Introduction}

Soil compaction causes a big problem in modern agriculture. Overuse of machinery and inadequate soil management leads to compaction. This compression increases the stress at the tire/soil (A. Elaoud et al., 2013) and reduced the physical fertility of the soil by reducing the storage and supply of water and nutrients, leading to requirement of additional fertilizer and increasing costs production.

Thus, the feasibility of a soil reflects its ability to accept the passage of vehicles and action tools (tractors, plows, etc.) [J.F. Billot et al., 1993]. The main causes of soil compaction are related to the development of mechanizations (0. Vitlox et al., 2002).

A study of experimental aspect (A. Elaoud et al., 2011; S. Chehaibi et al., 2006; S. Chehaibi et al, 2013) soil compaction at the wheel track of the tractor used for conducting various cultural operations is effected in Tunisia which shows the degree of compaction of agricultural soils based of mechanical and water parameters.

This paper shows a simulation developed with a base (TERRANIMO) shows the constraints wheel/soil on a selected soil.

\section{Methods and Materials}

\subsection{Methodology}

A platform used to evaluate settlements related to expenses in the soil profile the agricultural area. The methods of research, achievements and shortcomings associated with different components soil-machine including an evaluation compaction.

So, the objective of our research is to study the constraints on the soil produced by the weight of the machinery and by different inflation pressures wheels.

The evolution of the state of soil compaction has been followed by the theoretical behavior of the soil after passages of equipment.

\subsection{Presentation of the parameters}

The measurements will be performed initially to characterize soil conditions and parameters of tractors. In this context, the two tractors make a passage over the soil comprising $15 \%$ clay, $75 \%$ sand and $10 \%$ of silt.

The first tractor T1 of $170 \mathrm{HP}$ mass $6500 \mathrm{~kg}: 3900$ $\mathrm{kg}$ rear axle and $2600 \mathrm{~kg}$ front axle.

The second tractor T2 of 90 HP mass $4400 \mathrm{~kg}: 2850$ $\mathrm{kg}$ rear axle and $1550 \mathrm{~kg}$ front axle.

The third section tractor T3 of 330 HP mass 10500 $\mathrm{kg}$ : $6300 \mathrm{~kg}$ rear axle and $4200 \mathrm{~kg}$ front axle. 
Table 1 Characterization of the rear wheels

\begin{tabular}{|c|c|c|c|}
\hline Parameters & T1 & T2 & T3 \\
\hline Tyre Type & Driving wheel & Driving wheel & Driving wheel \\
\hline Constructor & Michelin & Michelin & Michelin \\
\hline Tire model & Omnibib & Omnibib & Omnibib \\
\hline Tire size & $580 / 70 \mathrm{R} 38$ & $520 / 70 \mathrm{R} 34$ & $650 / 85 \mathrm{R} 38$ \\
\hline Wheel load & 1950 & 1425 & 3150 \\
\hline Inflation pressure [bar] & 2 & 2 & 2 ou 1.6 \\
\hline
\end{tabular}

Table 2 Characterization of the front wheels

\begin{tabular}{|c|c|c|c|}
\hline Parameters & T1 & T2 & T3 \\
\hline Tyre Type & Driving wheel & Driving wheel & Driving wheel \\
\hline Constructor & Michelin & Michelin & Michelin \\
\hline Tire model & Omnibib & Omnibib & Omnibib \\
\hline Tire size & $480 / 70 \mathrm{R} 24$ & $420 / 70 \mathrm{R} 24$ & $600 / 70 \mathrm{R} 30$ \\
\hline Wheel load & 1300 & 775 & 2100 \\
\hline Inflation pressure [bar] & 0.8 & 0.8 & 0.8 ou 1.6 \\
\hline
\end{tabular}

In the first place, the inflation pressures of the front wheels and rear three tractors are respectively 0.8 bars and 2 bars.

In the second series of works, the processing wheel inflations variation is recorded at T3 from 0.8 to 1.6 bar for the front wheels 2 and 1.6 bar for the rear wheels.

\section{Experiments and Results}

The objective of this section is to simulate the footprint of soil/wheel of three tractors (T1, T2 and T3) respectively weight $6500 \mathrm{~kg}$ and $4400 \mathrm{~kg}$ and 10500 $\mathrm{kg}$.

Thus a variation in inflation pressure at the wheels of the tractor $\mathrm{T} 3$ is performed.

\subsection{Variation the weight of tractors}

Examination of the results of the theoretical effect of the passage of the first tractor T1 (Fig 1 and Fig 2) shows a fairly serious compaction at the rear wheel because of the constraints that exceed $100 \mathrm{kPa}$. This compaction can affect constraints that affect subsoil depth of about $50 \mathrm{~cm}$.

Thus examining the results of Figures 3 and 4 shows the theoretical compaction after the passage of the second tractor $\mathrm{T} 2$. This decline is less severe because the stresses at the rear wheel does not exceed $50 \mathrm{kPa}$. Undergoes compaction affects stresses in the subsoil depth of about $25 \mathrm{~cm}$.

Concerning the effect of the tractor T3, the stresses exceed $140 \mathrm{kPa}$ by assigning a depth of about $75 \mathrm{~cm}$ (Fig 5).

Indeed, we see a more intense compaction during the passage of the vehicle heavier.

Thus, the increased weight of the machine by $32 \%$ between T1 and T2 (27\% on the rear axle) produces a stress increase at tire/soil of approximately $100 \%$ contact.

Also, the increased weight of the vehicle by $58 \%$ between T2 and T3 (55 \% on the rear axle) causes an increase in constraints tire/soil of about $130 \%$.

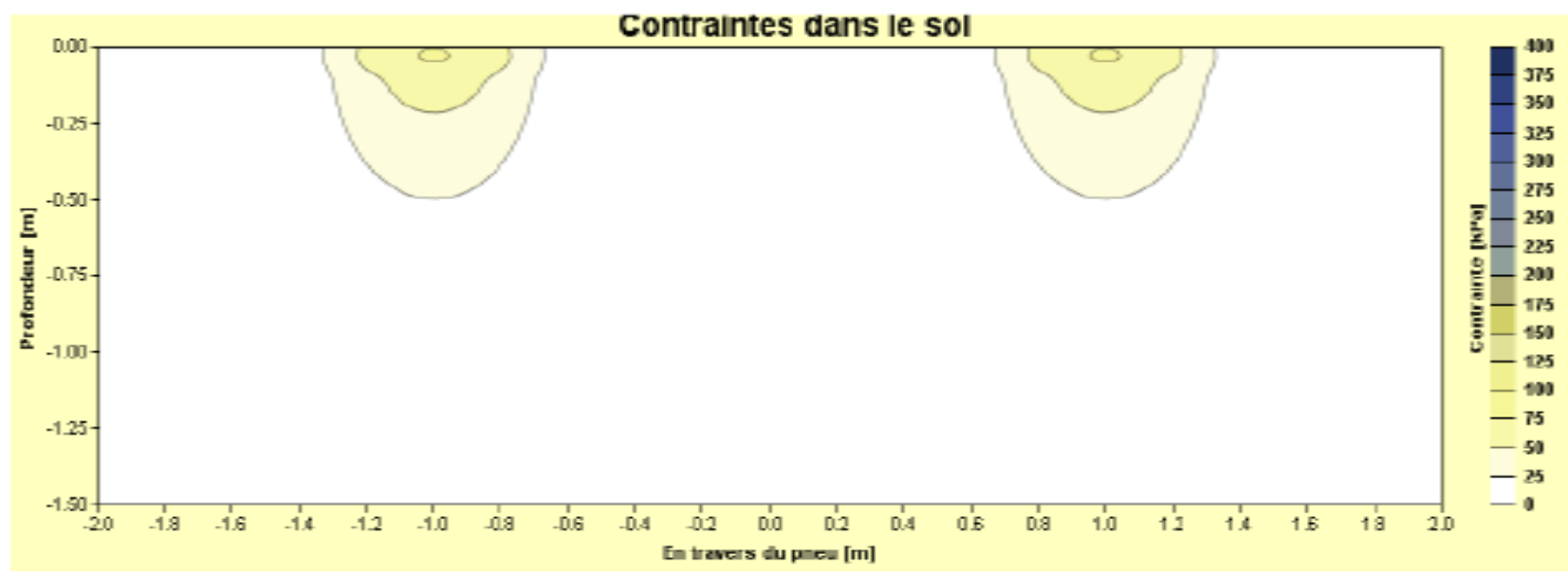

Figure 1 Stress in the soil affected by T1 (rear wheel) 


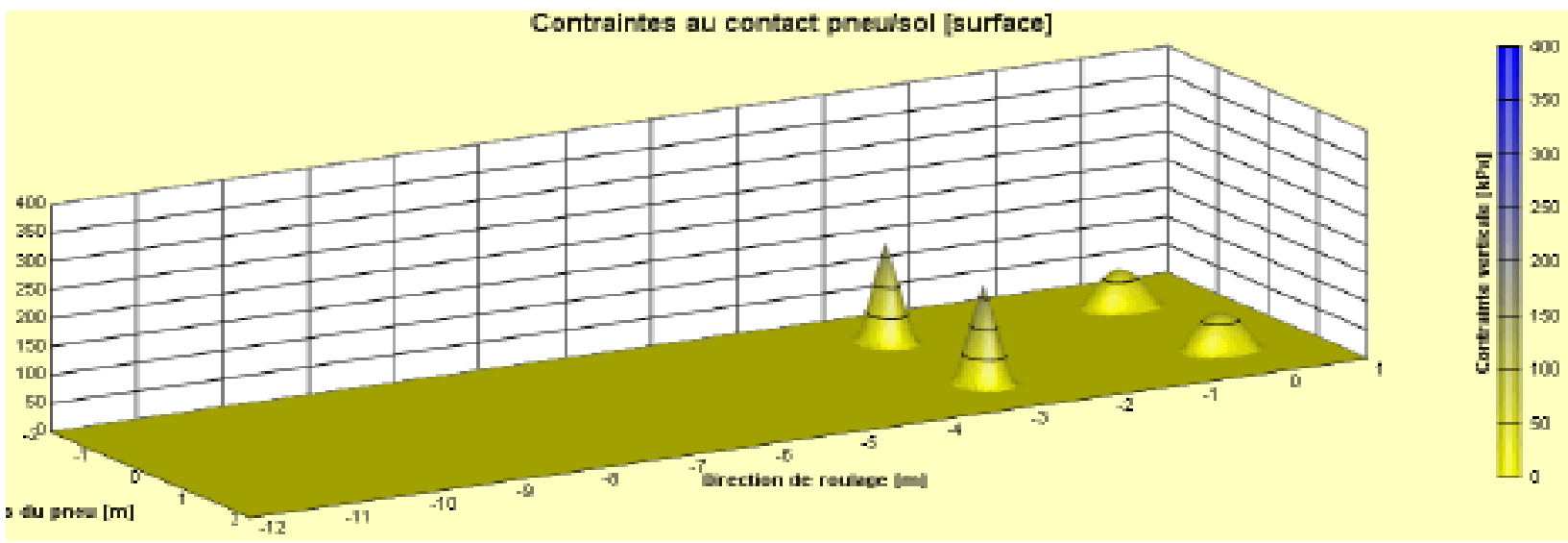

Figure 2 Stress at tire / soil contact 3D (T1)

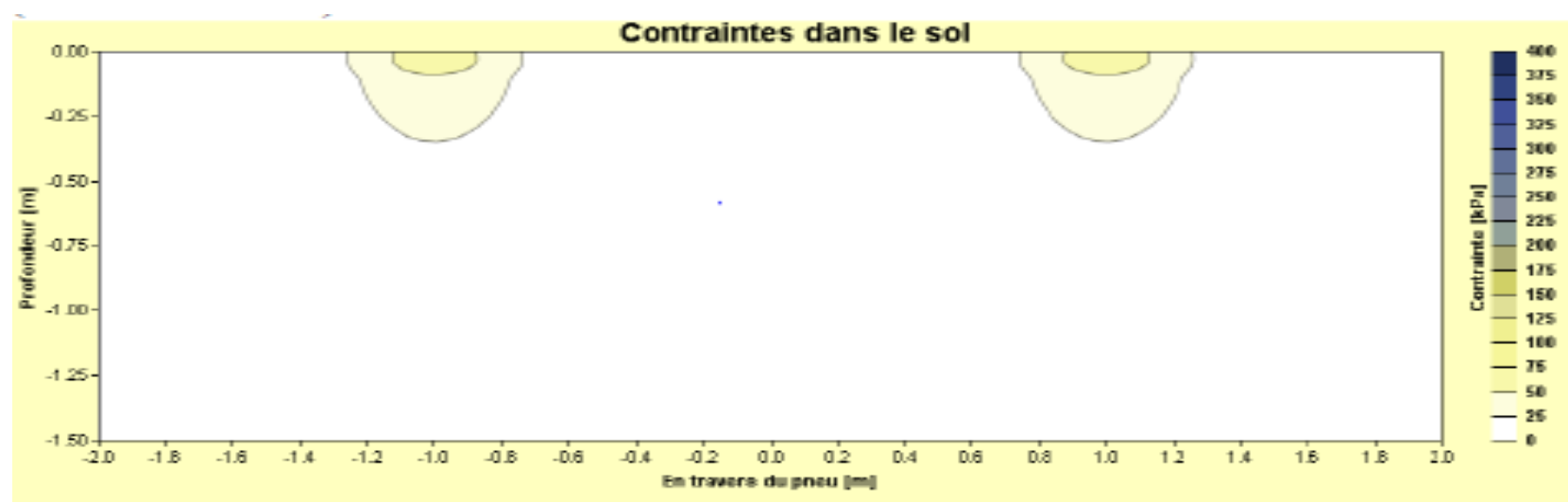

Figure 3 Stress in the soil performed by T2 (rear wheel)

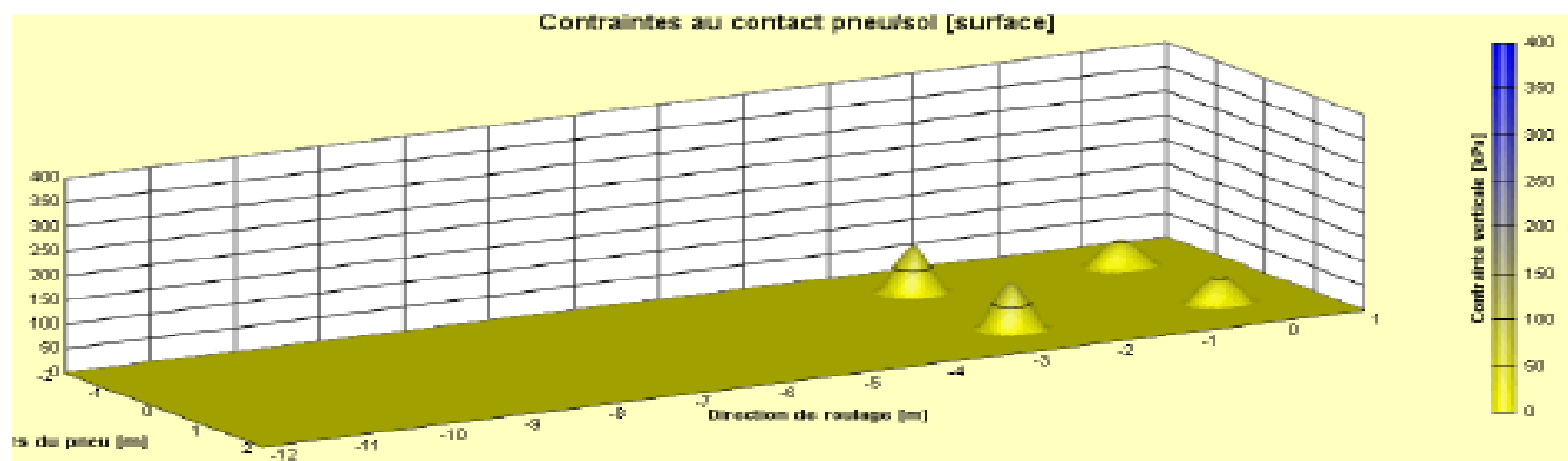

Figure 4 Stress at tire / soil contact 3D (T2)

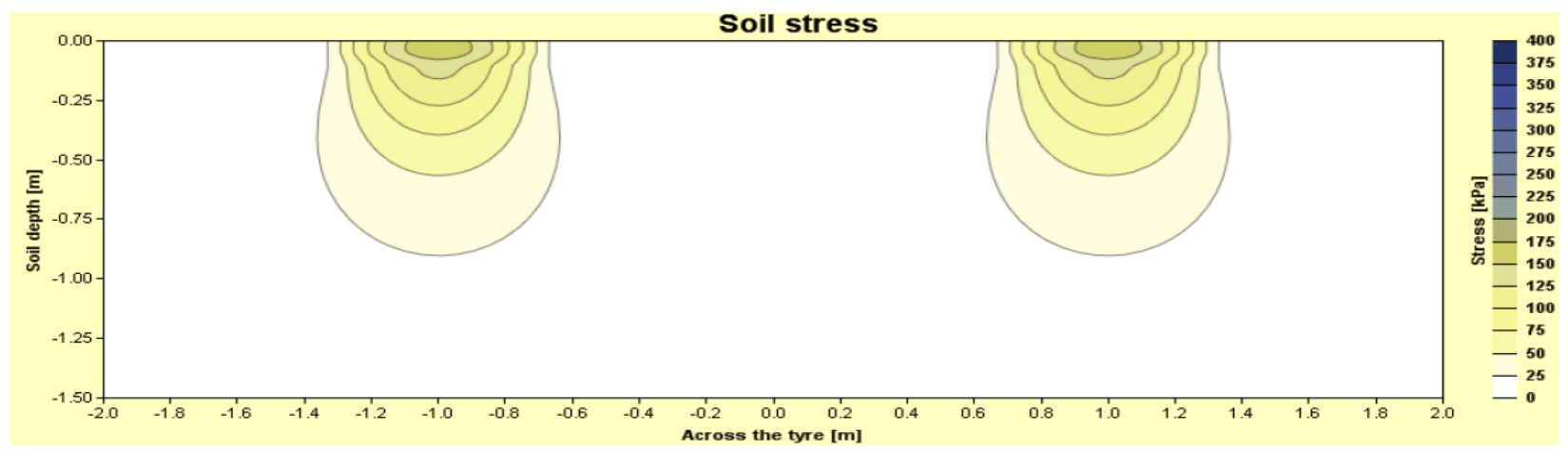

Figure 5 Stress in the soil conducted by tractor T3 (rear wheel: 2 bar) 


\subsection{Variation inflating wheels}

Furthermore, a study of the soil behavior according to the variation in inflation of the tractor wheels in T3 is performed as follows.

This part is to simulate constraints the wheel/soil using a tractor total weight $10500 \mathrm{~kg}$, and by varying the pressure of the rear wheels 1.6 bar to $0.8 \mathrm{bar}$ and the front wheels from 2 bar to 1.6 bar .

In a first state, the rear wheels of the tractor are inflated to $1.6 \mathrm{bar}$ and the front wheels and $0.8 \mathrm{bar}$ (Fig.6).

For the second case, the rear wheels are inflated to 2 bars and the front wheels at 1.6 bars (Fig. 7).

To better examine the results, a simulation is performed at the front and rear wheels in 2D.

Examination of the results of the theoretical effect of the passage of the tractor with different inflation pressures of the wheels.

Figures 8 and 9 show the contact surface and the impact of changes in pressure of the rear and front wheels.
This shows that increasing the inflation pressure, the contact surface the decrease and penetration resistance increases function of depth. (Figure 10 and 5)

A pressure of rear wheel 1.6 bars generates a maximum stress approximately $110 \mathrm{kPa}$. Thus increasing the pressure to 2 bar max the stress corresponds to $140 \mathrm{kPa}$.

This shows an increase tire pressure by $31 \%$ matches to an increase in the maximum stress at $27 \%$.

A pressure of front wheel $0.8 \mathrm{bar}$, generates a maximum stress approximately $50 \mathrm{kPa}$. Thus increasing the pressure to $1.6 \mathrm{bar}$ max the stress corresponds to $90 \mathrm{kPa}$ (approximately).

This shows an increase tire pressure by $100 \%$ matches to an increase in the maximum stress at $80 \%$.

Thus, we find that the soil layers are sensitive by increasing tire inflation. So we increasing the inflation pressure is increased the risk of compaction according to the depth (Figure 8, 9, 10 and 5).

Also the surface layer $(0-20 \mathrm{~cm})$ is the most compacted than the other layers in depth.

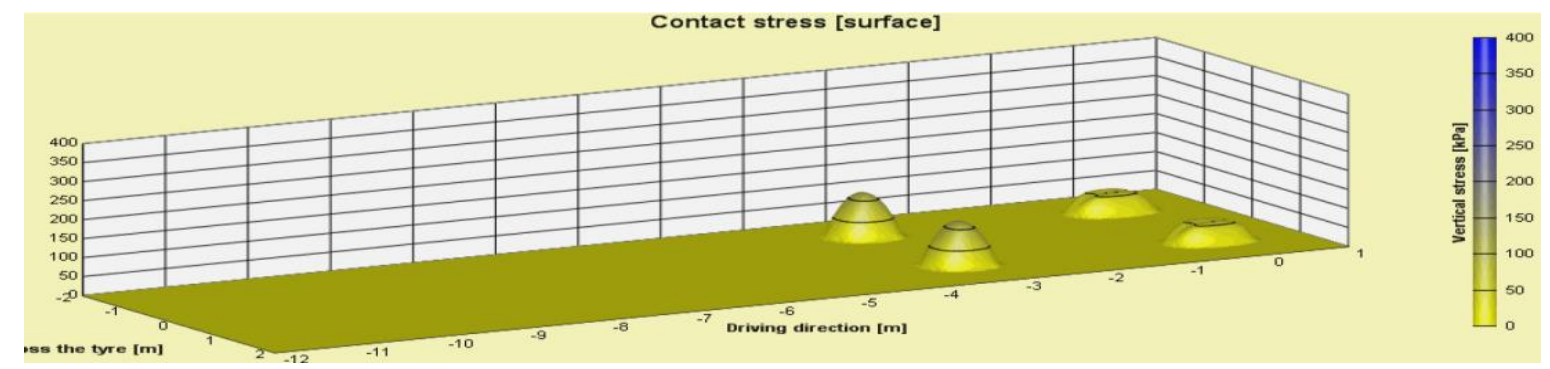

Figure 6 Stress at tire / ground contact in 3D: rear wheel inflated 1.6 bar and front wheel 0.8 bar (T3)

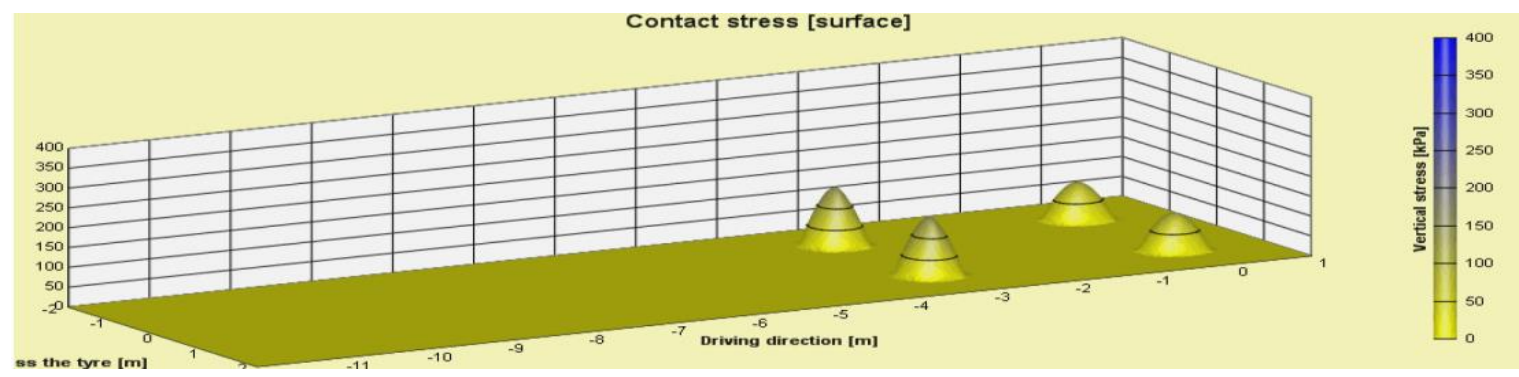

Figure 7 Stress at tire / ground contact in 3D: rear wheel inflated 2 bar and front wheel 1.6 bar

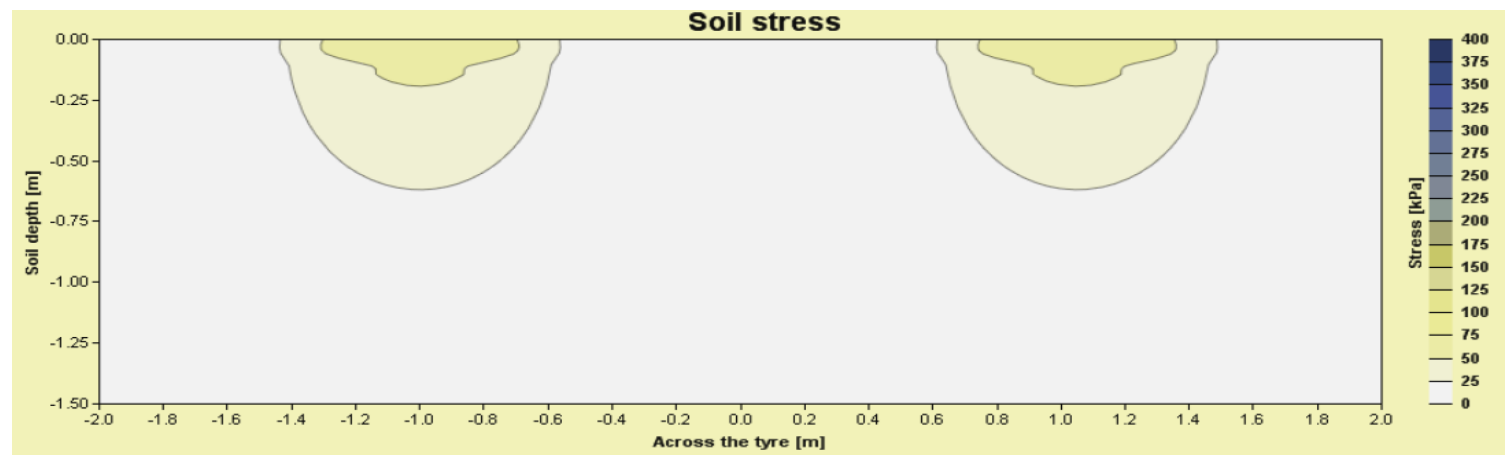

Figure 8. Stress in the soil conducted by the tractor for front wheel ( $0.8 \mathrm{bar})$ 


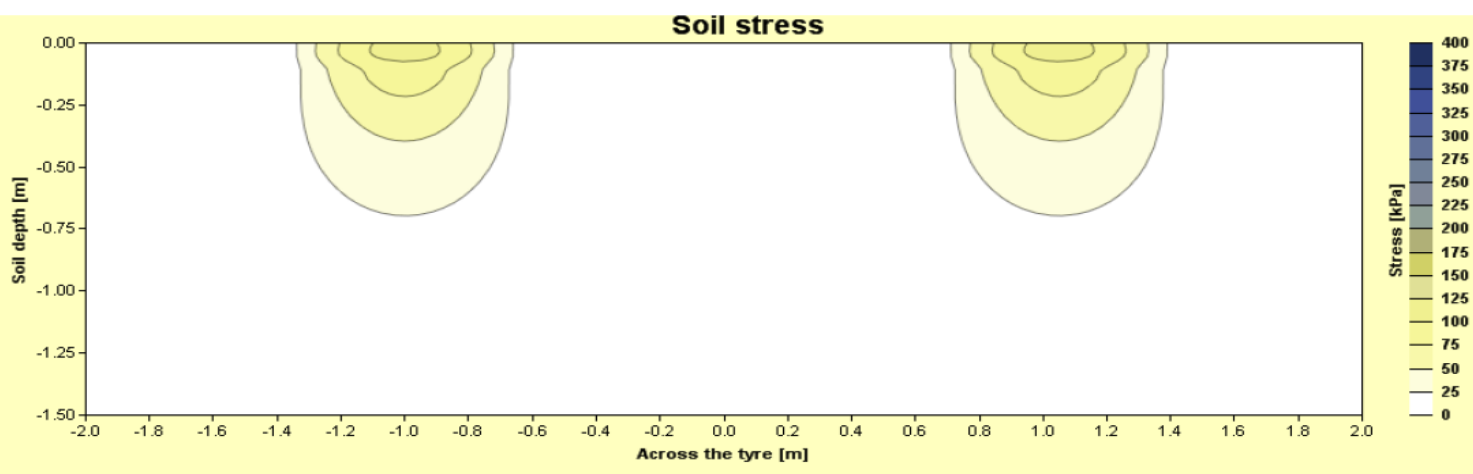

Figure 9 Stress in the soil conducted by the tractor for front wheel (1.6 bar)

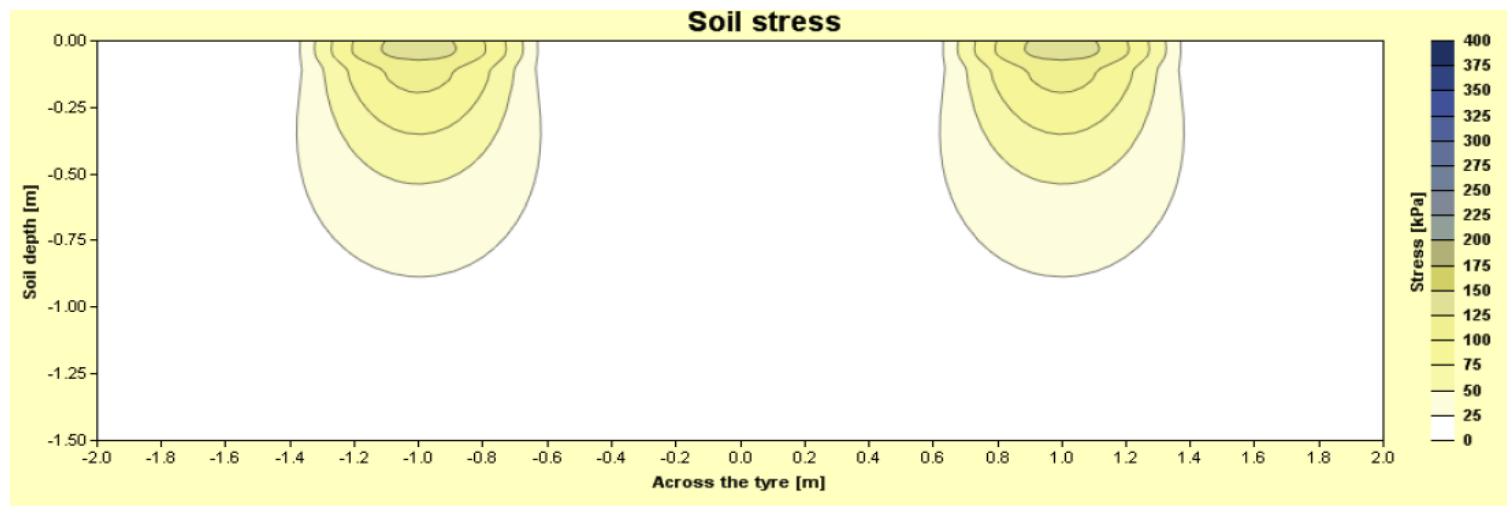

Figure 10 Stress in the soil conducted by the tractor for rear wheel (1.6 bar)

\section{Conclusion}

The theoretical study that we conducted on the effect of the mass of the vehicle, showed the influence of weight (on the rear axle and the front axle) on the degree of soil compaction.

Indeed, the increase in the weight of the vehicle 32 $\%$ (T1 and $\mathrm{T} 2$ ) causes an increase in stress to the contact tire/soil, and about $100 \%$ of a $55 \%$ increase (T2 and T3) results in increased constraints contact tire/ground about $130 \%$.

The theoretical study that we conducted on the effect of the mass of the vehicle, showed the influence of weight (on the rear axle and the front axle) on the degree of soil compaction.

Indeed, the increase rear tire pressure by $34 \%$ matches to an increase in the maximum stress at $40 \%$.

\section{References}

A. Elaoud, S. Chehaibi and M. Ben Amor (2013), Study of flow problems and those of soil compaction in an agricultural farm International Journal of Advance Industrial Engineering (IJAIE). ISSN 2320 -5539-Vol.1, No.1, p 13-19.

J.F. Billot, M. Aubineau and R. Autelet (1993), Les matériels de travail du sol, semis et plantation, CEMAGREF/ITCF/TEC \& DOC Paris, $384 \mathrm{p}$.

0. Vitlox and S. Loyen, (2002), Conséquences de la mécanisation sur la compaction du sol et l'infiltration de l'eau, Compte rendu de la journée d'étude: Erosion hydrique et coulées boueuses en Région allonne, pp. 45-58.

A. Elaoud, S. Chehaibi (2011), Soil compaction due to tractor traffic, Journalof Failure Analysis and Prevention, JFAP- DOI 10.1007/s11668-011-9479-3, p539-545

S. Chehaibi, E. Hamza, J. Pieters and R. Verschoore (2006), Analyse comparative du tassement du sol occasionné par les passages de deux types de tracteurs, Annales de l'INRGREF, $\mathrm{n}^{\circ} 8,157-170$.

S. Chehaibi, K. Abrougui, A. Elaoud, M. Chaabani and M. Khelif (2013), Effects of workingdepth on mechanical aeration of a grassy soil and its impact on the plant root behavior, Herald Journal of agriculture and Food Science Research HJAFSR-12-019, ISSN 2350 - 2185, vol 2 p 063-069. 